\title{
Sexual and reproductive health among young female sex workers in Bangladesh brothels-Baseline findings from Link Up
}

Population Council

Follow this and additional works at: https://knowledgecommons.popcouncil.org/departments_sbsr-hiv

Part of the Demography, Population, and Ecology Commons, Family, Life Course, and Society Commons, Gender and Sexuality Commons, International Public Health Commons, and the Women's Health Commons How does access to this work benefit you? Let us know!

\section{Recommended Citation}

Population Council. 2015. "Sexual and reproductive health among young female sex workers in Bangladesh brothels-Baseline findings from Link Up," Study brief. Washington, DC: Population Council. 


\section{SEXUAL AND REPRODUCTIVE HEALTH AMONG YOUNG FEMALE SEX WORKERS IN BANGLADESH BROTHELS-BASELINE FINDINGS FROM LINK UP}

In Bangladesh, sex work is legal, with thousands of female sex workers residing and working in red light districts and licensed brothels. In each of the country's official brothels, hundreds of women live in large, densely populated communities that are situated in and around urban alleys. ${ }^{1}$ Limited available data suggest that female sex workers often engage in unsafe sex, particularly with non-paying sex partners. ${ }^{2}$ These vulnerable young women-most of whom retire by age $30^{1}$-are typically of reproductive age and extremely vulnerable to unintended pregnancy. Frequent unsafe sex with multiple partners also places female sex workers at elevated risk of HIV and sexually transmitted infections (STIs). HIV prevalence among Bangladeshi female sex workers is about 1 percent, with syphilis prevalence at 3 percent. ${ }^{2}$ To address their sexual and reproductive health and rights (SRHR) needs, local nongovernmental organizations PIACT Bangladesh and Marie Stopes Bangladesh are implementing a brothel-based program for female sex workers as part of the global Link Up project.

Link Up implementing partners and Marie Stopes Bangladesh are working in eight brothels in seven districts (Rajbari, Jessore, PatuakhaIi, Bagerhat, Tangail, Faridpur, and Khulna). Trained female sex worker peer educators in the brothels will provide face-to-face peer education on SRHR and HIV issues, including referrals to on-site and off-site health care services where they can access HIV testing and counseling, STI screening and treatment, condoms, and other contraceptive methods.

The Population Council is conducting an evaluation of this brothel-based Link Up project to assess its effectiveness and to inform programming and polices. This brief presents key baseline survey findings, which describes female sex workers in the eight study brothels in terms of their sexual and reproductive health knowledge and behavior.

\section{STUDY METHODOLOGY}

The study team conducted the baseline survey in July 2014. Trained researchers interviewed all eligible female sex workers aged 18 to

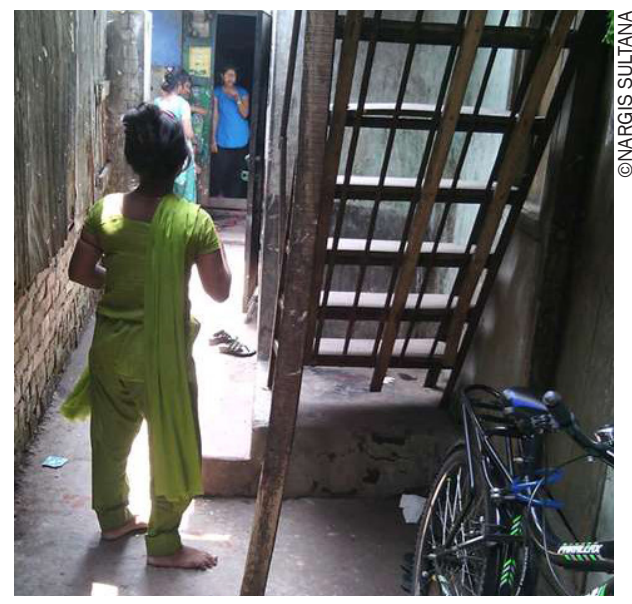

As part of Link Up, female sex worker peer educators in the brothels will provide education on sexual health and HIV issues.

\section{KEY MESSAGES}

Consistent condom use-either alone or combined with other effective contraception-should be promoted with both paying and non-paying sex partners.

Female sex workers have the desire and right to control the timing and spacing of pregnancy.

Programs and policies should ensure that female sex workers have knowledge of-and access to-safe options to terminate pregnancies, as well as comprehensive post-abortion care. 
24, who were currently living in the brothels, and who had sold sex in the past three months. A total of 1,071 female sex workers were recruited. The face-to-face interviews consisted of closed-ended questions on sociodemographic characteristics, use of family planning, knowledge of HIV, condom use at last sex, consistent condom use in the past 30 days, HIV testing, and STI symptoms.

\section{STUDY POPULATION}

As shown is Table 1, participants had a median age of 21 years, about half (51 percent) had no education, and one-third had primary education. About 40 percent of the female sex workers reported currently having a primary male sexual partner (husband or boyfriend). Nearly three-quarters of the participants had no children, 23 percent had one child, and 4 percent had more than one child.

\section{KEY FINDINGS}

\section{Client volume}

All female sex workers had sold sex in the previous seven days, reporting a median of 20 clients. Although 40 percent said that they had a primary, intimate partner, only 14 percent of them reported having sex with non-paying clients in the past 30 days.

\section{Reproductive history and family planning}

Over half of participants reported that they had ever been pregnant. Twenty-six women (2 percent) reported

TABLE 1 STUDY POPULATION ( $\mathrm{N}=1,071)$

\begin{tabular}{lc}
\hline VARIABLE & TOTAL \% (N) \\
\hline Age [Median (min-max)] & $21(18,24)$ \\
Education & \\
$\quad$ No education & $50.9(545)$ \\
$\quad$ Primary & $32.6(349)$ \\
Above primary & $16.5(177)$ \\
Marital status & \\
$\quad$ Never married & $52.8(565)$ \\
$\quad$ Married & $5.9(63)$ \\
Divorced/widowed & $41.4(443)$ \\
\# years living in the brothel [Median (IQR)] & $2.0(1,5)$ \\
Had a primary partner & \\
$\quad$ No & $60.6(649)$ \\
$\quad$ Yes & $39.4(422)$ \\
Age started selling sex [Median (IQR)] & $17.0(14,19)$ \\
\hline
\end{tabular}

that they were currently pregnant. More than half (56 percent) stated that they wanted to have another child at some point in the future, among whom 33 (6 percent) wished to get pregnant "soon/now."

Among those women with need for family planning $(n=976)-$ which excludes those who had not had sex in the past 90 days, who were currently pregnant, unable to get pregnant, or who wished to get pregnant "soon/ now,"-the vast majority ( $n=955,98$ percent) reported using some method to prevent pregnancy. Ninety-two percent reported using male condoms, but less than half used them consistently, as discussed previously. Sixty percent reported using non-barrier modern contraceptive methods, the most common of which were the pill (44 percent) and injectable (15 percent) (Table 2). About 7 percent reported ever having used emergency contraceptive pills and 92 percent felt confident they could obtain contraceptives if needed.

\section{Menstrual regulation and abortion}

Induced abortion is illegal in Bangladesh except when performed to save a woman's life ${ }^{3}$; however, menstrual regulation (MR) procedures are permissible in order to induce menstruation among women who think they may be pregnant. Government-approved MR providers can perform the procedure up to 10 weeks after

\section{TABLE 2 CONTRACEPTIVE USE*}

\begin{tabular}{lc}
\hline VARIABLE & $\mathrm{N}(\%)$ \\
\hline Any contraceptive method $(\mathrm{n}=976)$ & $955(97.8)$ \\
Any modern method $(\mathrm{n}=976)$ & $953(97.6)$ \\
Method mix among family planning users $(\mathrm{n}=955)^{* *}$ \\
Male condom & $881(92.0)$ \\
Female condom & $9(0.9)$ \\
Any non-barrier modern method*** & $580(60.0)$ \\
Pill & $418(43.7)$ \\
Injectable & $148(15.2)$ \\
Implant & $14(1.5)$ \\
Intrauterine device & $1(0.1)$ \\
Female sterilization & $4(0.4)$ \\
Male sterilization & $0(0.0)$ \\
Fertility awareness methods & $1(0.1)$ \\
Lactational amenorrhea method & $3(0.3)$ \\
Withdrawal & $25(2.6)$
\end{tabular}

*Among those who had had sex in the past 90 days, were able to get pregnant, not currently pregnant, and did not wish to get pregnant "soon/now" (n=976).

${ }^{* *}$ Respondents could select more than one method

${ }^{* * *}$ Non-barrier modern methods include the pill, injectable, intrauterine device, female sterilization, or male sterilization. 
a missed period, using a MR medication regimen or surgical procedures. ${ }^{4}$ Among those who had ever been pregnant, 48 percent reported having had any kind of abortion (whether MR or an induced abortion at more than 10 weeks gestation). About 18 percent of participants reported ever having had an MR using medication (typically misoprostol, at less than 10 weeks gestation); 14 percent reported having had a surgical MR (typically using manual vacuum aspiration, at less than 10 weeks gestation); and 19 percent reported having had an induced abortion (more than 10 weeks). Among those participants who had ever terminated a pregnancy, 42 percent experienced complications that required postabortion care.

\section{HIV knowledge}

About 92 percent knew that HIV can be transmitted through having unprotected sex; 30 percent through sharing needles and syringes; 20 percent through blood transfusion; and 7 percent through mother-to-child transmission.

\section{Condom use}

The majority of female sex workers (92 percent) stated they used condoms the last time they had sex with a paying client. However, just 54 percent reported consistent condom use with paying clients in the past 30 days, defined as always using condoms during that time. With non-paying sex partners, 40 percent reported condom use at last sex, and 15 percent reported consistent use in the past 30 days (Figure 1).

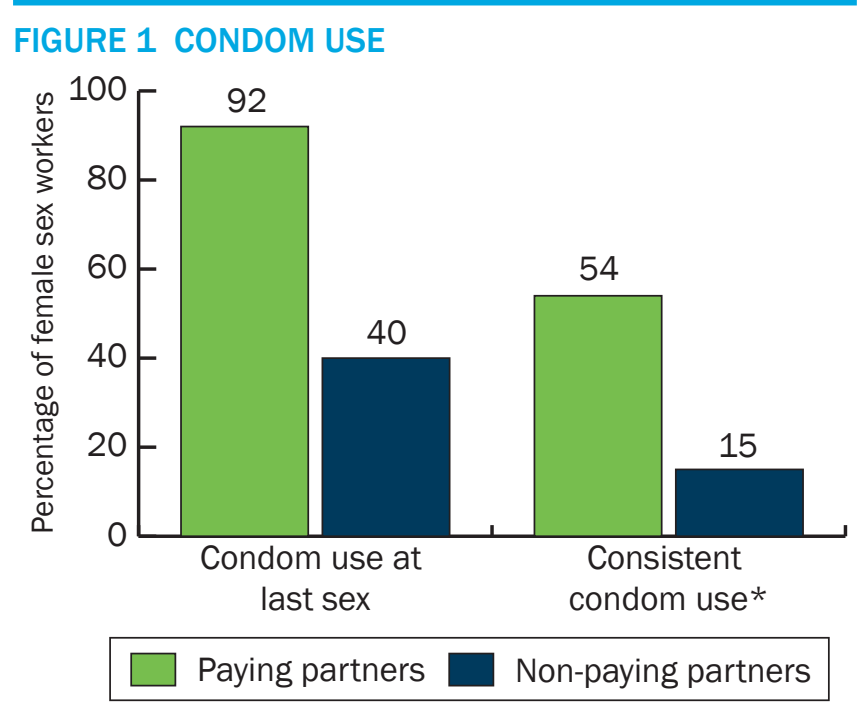

*Always used condoms in the past 30 days
Only 20 percent of women perceived that they were at high risk of HIV infection (stating that they were likely or highly likely to acquire HIV). Among those who had a low self-perceived risk of getting HIV, most felt this way because they used condoms with partners that they do not trust (90 percent), and 70 percent said they were at low risk because they always used condoms.

\section{HIV testing}

Less than half of participants (45 percent) had ever tested for HIV, and 31 percent had been tested at least once in the past 12 months. Of those who tested in the past 12 months, 88 percent received the test result at the last test. Researchers did not request that participants divulge their test results. Among those who had never been tested, the most frequently stated reason for not having tested for HIV was that they felt "healthy/not sick" (79 percent). Among those who had never tested, 37 percent said they knew a place in the community where they could get tested (Figure 2).

\section{STI symptoms}

Interviewers asked participants if they had experienced various symptoms associated with STIs in the past six months. The most commonly reported symptoms were lower abdominal pain (34 percent), abnormal vaginal discharge (25 percent), and burning during urination (17 percent).

\section{FIGURE 2 HIV TESTING*}

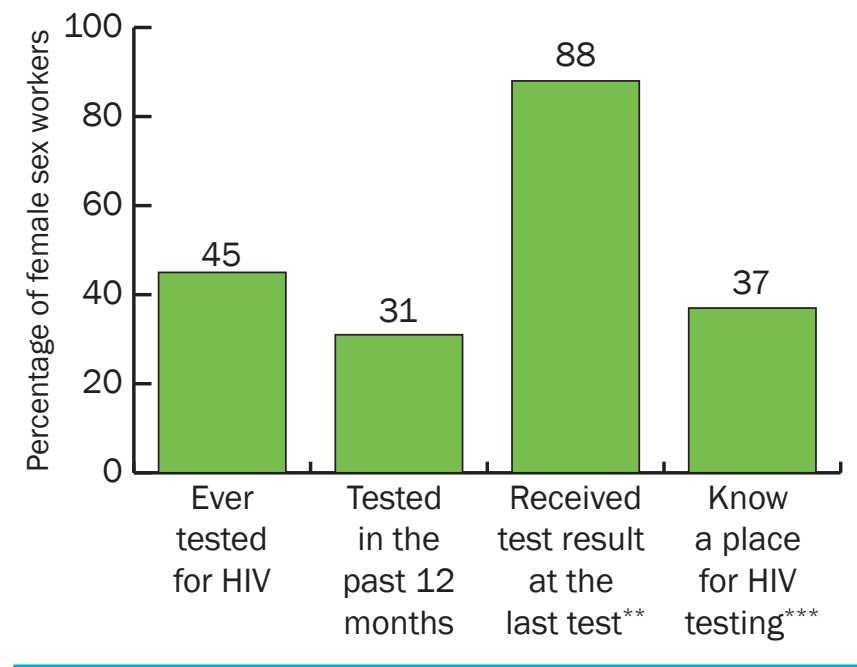

\footnotetext{
*Among the 1,040 who responded to HIV testing questions

${ }^{* *}$ Among the 470 participants who had ever been tested

${ }^{* * *}$ Among the 570 women who had never been tested
} 


\section{Sexual and reproductive health service utilization}

Almost all participants (99 percent) reported that they were receiving some form of sexual and reproductive health services, most frequently from Population Services and Training Center (62 percent) and PIACT Bangladesh (21 percent). Among the 90 percent who had ever been contacted by a peer educator, less than 20 percent had received such contact within the past six months. Among those who had ever been contacted by a peer educator, 3 percent reported receiving some form of peer referral to on-site or off-site clinics during the past six months.

\section{PROGRAM IMPLICATIONS AND RECOMMENDATIONS}

Findings from the Link Up baseline survey highlight many unmet sexual and reproductive health, and HIV and STI prevention needs among Bangladeshi female sex workers who work and live in brothels. Although a large majority of women reported using family planning methods, condoms were by far the most popular method, and condom use was inconsistent. Dual method use or consistent condom use is essential to ensuring that female sex workers are protected against both unintend- ed pregnancy and disease. High prevalence of abortion and STI symptoms coupled with inconsistent condom use indicate that participants regularly have unprotected sex.

Although peer outreach in Bangladesh brothels is not a new strategy, these baseline findings suggest that peer educators have not yet played an active role in referring female sex workers to needed clinical services such as contraceptive counseling or HIV and STI testing. Link Up strategies such as on-site health care services, training of health care providers at affiliated off-site Link Up facilities, and active peer referral to on- and off-site clinical care are promising approaches to improve the sexual and reproductive health of female sex workers in Bangladesh brothels.

\section{REFERENCES}

${ }^{1}$ Islam, A. and R. Smyth. 2012. "The economic returns to good looks and risky sex in the Bangladesh commercial sex market," The B.E. Journal of Economic Analysis \& Policy 12(1): Article 22.

${ }^{2}$ IEDCR and icddr'b. 2011. National HIV Serological Surveillance. Bangladesh: National AIDS/STD Programme (NASP). http://www.aidsdatahub.org/ sites/default/files/documents/HSS_9th_round_2011.pdf

${ }^{3}$ Bangladesh Penal Code, Act no. XLV of 1860: Ch. XVI, § 313.

${ }^{4}$ Guttmacher Institute. 2012. Menstrual Regulation and Induced Abortion in Bangladesh. http://www.guttmacher.org/pubs/FB-Bangladesh-MR.pdf.

Link Up aims to improve the sexual and reproductive health and rights (SRHR) of one million young people affected by HIV across five countries in Africa and Asia. The project is being implemented by a consortium of partners led by the International HIV/AIDS Alliance.

Link Up consortium partners

- ATHENA Network

- Global Youth Coalition on HIV/AIDS

- International HIV/AIDS Alliance

- Marie Stopes International in Bangladesh, Myanmar and Uganda

- Population Council

Other key collaborators include UNFPA, UNESCO and AIDS Fonds. Funded by the Ministry of Foreign Affairs of the government of the Netherlands (BUZA).

To follow the progress of Link Up, visit www.link-up.org
- STOP AIDS NOW!

- Alliance Burundaise Contre le SIDA in Burundi

- Organisation for Support Services for AIDS (OSSA) in Ethiopia

- Alliance Myanmar
- Community Health Alliance Uganda
POPULATION COUNCIL

Ideas. Evidence. Impact.
The Population Council confronts critical health and development issues-from stopping the spread of HIV to improving reproductive health and ensuring that young people lead full and productive lives. Through biomedical, social science and public health research in about 50 countries, the Council works with our partners to deliver solutions that lead to more effective policies, programs, and technologies to improve lives worldwide. Established in 1952 and headquartered in New York, the Council is a nongovernmental, nonprofit organization with an international board of trustees.

Suggested citation: Population Council. 2015. "Sexual and reproductive health among young female sex workers in Bangladesh brothels-Baseline findings from Link Up," Link Up Study Brief. Washington, DC: Population Council. 